\title{
Cinacalcet and primary hyperparathyroidism: systematic review and meta regression
}

\author{
Cheng Han Ng1,*, Yip Han Chin ${ }^{1, *}$, Marcus Hon Qin Tan ${ }^{1}$, Jun Xuan Ng${ }^{1}$, Samantha Peiling Yang ${ }^{1,2}$, Jolene Jiayu Kiew ${ }^{2}$ \\ and Chin Meng Khoo (D) 1,2
}

${ }^{1}$ Yong Loo Lin School of Medicine, National University of Singapore, Singapore

2Department of Medicine, National University Hospital, Singapore

Correspondence should be addressed to C M Khoo: MDCKCM@nus.edu.sg

*( $\mathrm{C} \mathrm{H} \mathrm{Ng}$ and $\mathrm{Y} \mathrm{H}$ Chin contributed equally to this work)

\begin{abstract}
Purpose: Primary hyperparathyroidism (PHPT) is a common condition affecting people of all ages and is mainly treated with parathyroidectomy. Cinacalcet has been widely used in secondary or tertiary hyperparathyroidism, but the use of cinacalcet in PHPT is less clear.

Methods: Searches were conducted in Medline and Embase for cinacalcet use in PHPT from induction to 10 April 2020. Articles and conferences abstracts describing the use of cinacalcet for PHPT in prospective or retrospective cohorts and randomized controlled trials restricted to English language only. We initially identified 1301 abstracts. Each article went extraction by two blinded authors on a structured proforma. Continuous outcomes were pooled with weight mean difference (WMD). Quality of included articles was assessed with Newcastle Ottwa Scale and Cochrane Risk of Bias 2.0.

Results: Twenty-eight articles were included. Normalization rate of serum Ca levels was reported at $90 \%$ (Cl: 0.82 to 0.96$)$. Serum levels of $\mathrm{Ca}$ and PTH levels were significantly reduced (Ca, WMD: 1.647, Cl: -1.922 to -1.371 ; PTH, WMD: $-31.218, \mathrm{Cl}:-41.671$ to -20.765 ) and phosphate levels significantly increased (WMD: $0.498, \mathrm{Cl}: 0.400$ to 0.596 ) after cinacalcet therapy. The higher the baseline Ca levels, the greater Ca reduction with cinacalcet treatment. Age and gender did not modify the effect of cinacalcet on serum Ca levels.

Conclusion: The results from the meta-analysis support the use of cinacalcet as an alternative or bridging therapy to treat hypercalcemia in people with PHPT.
\end{abstract}

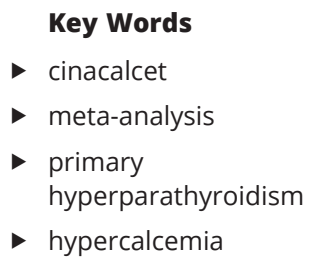

\section{Introduction}

Primary hyperparathyroidism (PHPT) is a common endocrine disorder that is caused by excessive or inappropriate parathyroid hormone (PTH) secretion with simultaneous derangement of both phosphate and calcium metabolism. PHPT is more prevalent in both elderly and female patients (1) and is mainly caused by parathyroid adenoma, but can also be due to parathyroid hyperplasia, parathyroid carcinoma, and rare genetic abnormalities such as multiple endocrine neoplasia (MEN) syndrome.
Patients with PHPT might present with cardinal signs of hypercalcemia with significant involvement from both renal and skeletal system presenting with recurrent nephrolithiasis, fragility fractures, or both (2).

Parathyroidectomy is the current gold standard treatment for PHPT with resolution in hypercalcemia and hypophosphataemia. However, there is a subset of patients who might not be suitable candidates for surgery, or have refractory hypercalcemia despite parathyroidectomy, https://ec.bioscientifica.com

https://doi.org/10.1530/EC-20-0221 (c) 2020 The authors Published by Bioscientifica Ltd

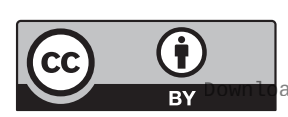

This work is licensed under a Creative Commons Attribution 4.0 International License. ded from Bioscientifica.com at 04/26/2023 11:25:32AM 
or prefer non-surgical intervention. Also, surgery might be delayed due to unforeseen circumstances, for example, the recent COVID-19 pandemic has resulted in postponement of non-essential surgeries such as parathyroidectomy. Thus, an effective non-surgical option as a bridging therapy to parathyroidectomy would be required to control hypercalcemia while awaiting surgery.

Cinacalcet is a positive allosteric modulator of the calcium sensing receptor (CaSR) that increases the sensitivity of the CaSR on the parathyroid glands, thereby reducing PTH secretion and serum Ca levels (3). Cinacalcet is widely used in patients with secondary or tertiary hyperparathyroidism. Its benefit in patients with PHPT is less known. Here, we conducted a meta-analysis alongside a case series to pool evidence in the use of cinacalcet in controlling hypercalcemia from PHPT.

\section{Materials and methods}

\section{Search strategy}

We adhered to the PRISMA guidelines of the synthesis of this review (4). Searches were conducted on 5 April 2020 on electronic database Medline and Embase. Keywords and thesaurus terms were used in the search for 'Cinacalcet' and 'Primary hyperparathyroidism' and abstracts were complied with duplicates removed in Endnote X9 (Supplementary Table 1, see section on supplementary materials given at the end of this article).

\section{Selection criteria and outcomes}

The meta-analysis focuses on the use of cinacalcet in the treatment of hypercalcemia due to PHPT including primary adenoma and multiple endocrine neoplasia syndromes (MENS). We excluded the use of cinacalcet for parathyroid carcinoma and secondary or tertiary hyperparathyroidism in the context of chronic kidney disease. A variety of study designs were included including randomized controlled trials (RCTs), prospective and retrospective single arm cohort studies. Demographic data (sample size, age, gender, medical conditions) regarding interventional population were extracted. The main outcomes included serum $\mathrm{Ca}$, PTH and phosphate before and after cinacalcet treatment, as well as the rate of normalization in $\mathrm{Ca}$ and PTH levels. When studies do not report the mean and S.D., transformation of the data was conducted through prevailing formulas $(5,6,7)$. We also reported the reasons for prescribing cinacalcet, discontinuation rate and rationale, and adverse reactions related to cinacalcet treatment.

\section{Statistical analysis and quality assessment}

Three type of analyses were conducted with the collected data. First, a meta-analysis of proportion was undertaken for binary data after a Freeman-Turkey double arcsine transformation to stabilize variance before analysis was pooled with DerSimonian and Laird random effects $(8,9)$. For continuous variables on the laboratory parameters of only post-cinacalcet use, the inverse variance method was used in pooling proportions. Next, pairwise comparisons were conducted with DerSimonian and Laird random effects regardless of heterogeneity measures $\left(\mathrm{I}^{2}\right.$, Cochran $\mathrm{Q}$ test and Tau) for laboratory parameters between before and after cinacalcet use and cinacalcet compared to placebo (9). Continuous data were pooled with weight mean difference (WMD). Lastly, meta regression with random effects restricted maximum likelihood model was used to explore heterogeneity when sufficient data were available $(n \geq 10)$ (10). Knapp-Hartung variance estimator was used in the readjustment of variance (11). Publication bias was explored with Egger's regression test (12). Statistical significance was considered when $P<0.05$. Quality assessment of included articles was done by the Newcastle Ottawa scale for non-randomized studies, and randomized controlled trial (RCTs) was done with the Cochrane Risk of Bias 2.0 tool $(13,14)$. Visual representation of the risk of bias was done through the robvis tool (15).

\section{Results}

\section{Meta-analysis}

\section{Literature review}

A total of 1301 articles were identified after duplicates removal, and eventually 28 articles were included in the review $(16,17,18,19,20,21,22,23,24,25,26,27,28$, $29,30,31,32,33,34,35,36,37,38,39,40,41,42,43)$, of which 8 were conference proceedings $(20,24,25,30$, 31, 32, 41, 42) (Fig. 1). In total, 823 patients underwent treatment with cinacalcet and 722 completed treatment for either PHPT $(16,17,18,20,21,22,23,24,25,26,27$, $28,29,30,31,33,34,35,36,37,38,39,40,41,42,43)$ or MENS $(19,24,26,28,29,32)$. A collective total of 101 patients did not complete treatment. Majority of included articles use cinacalcet as a monotherapy, while a minority

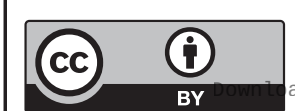

This work is licensed under a Creative Commons Attribution 4.0 International License. 


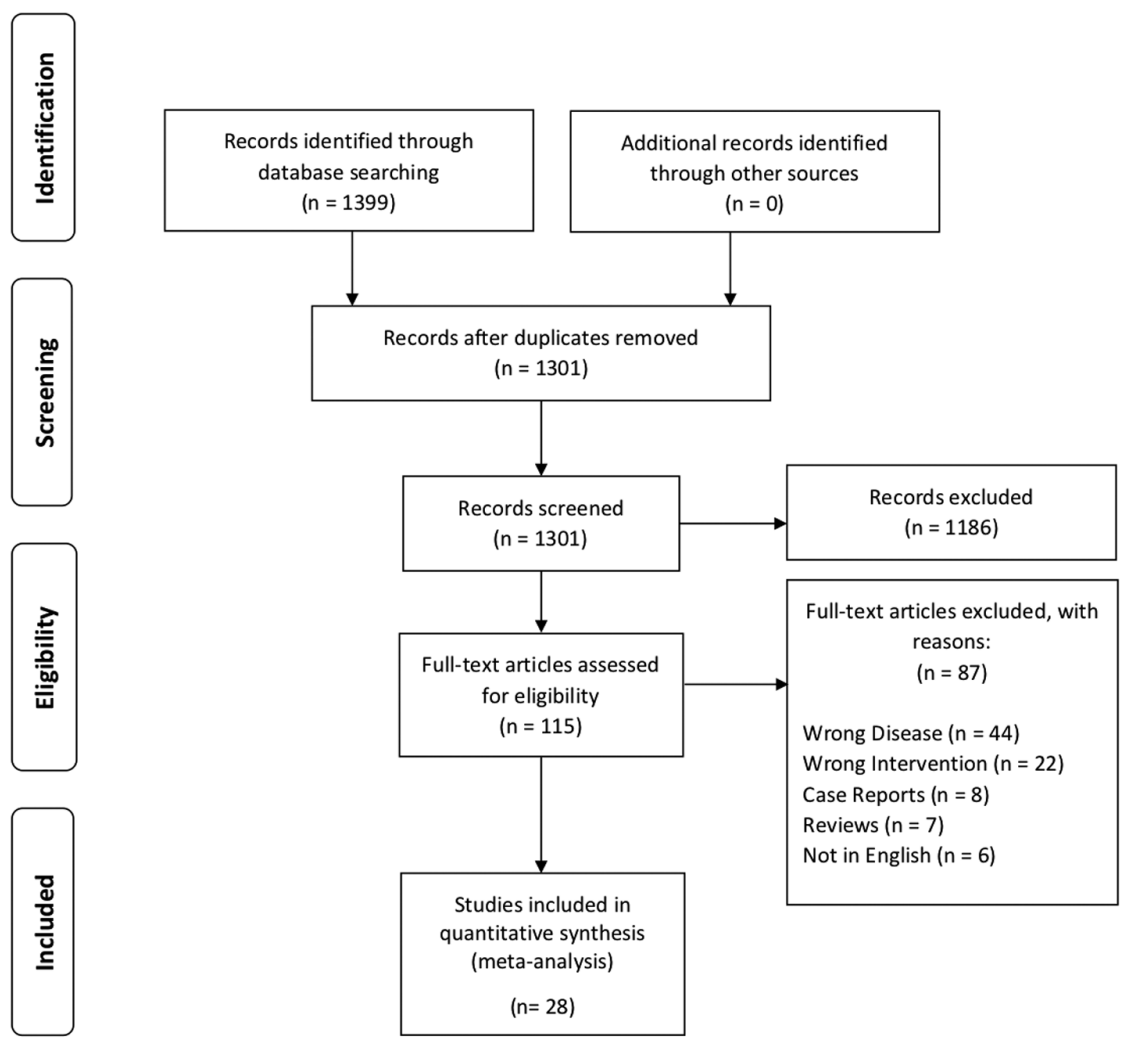

Figure 1

PRISMA flowchart. $(n=9)$ had subsets of patients with adjunct medications $(17,21,22,24,26,29,33,39,41)$. Four articles were randomized controlled trials comparing cinacalcet with placebo $(22,28,37,38)$, while majority were prospective and retrospective cohort studies. Majority of studies were conducted in America and Europe with exception to two studies $(16,17)$ (Japan and Israel). Table 1 summarizes the characteristics of included articles and the risk for bias for RCTs is presented in Fig. 2.

\section{Indications}

The majority of indications for cinacalcet treatment are either for contraindication or refusal for surgery (19, $21,22,24,26,27,28,29,31,32,33,35,36,39,43)$, reduction in serum Ca levels prior to surgery $(18,20,26$, $27,31,40,41)$ or to treat refractory hypercalcemia despite parathyroidectomy $(16,19,22,27,28,29,31,32,35,36$, $38,41,43)$.

\section{Effectiveness of cinacalcet treatment}

\section{Calcium (mg/dL)}

With cinacalcet use, pooled proportions found that normalization rate of serum $\mathrm{Ca}$ was reported at
90\% (CI: 0.82 to 0.96). Pooled analysis of serum Ca levels after cinacalcet treatment averaged at 9.733 (CI: 9.554 to 9.912 ). Comparing before and after cinacalcet treatment, cinacalcet significantly reduced the mean serum Ca level by 1.647 (CI: -1.922 to $-1.371, P<0.001$, Fig. 3) from baseline. A subgroup analysis was done to examine the effect of cinacalcet between baseline values that was greater or smaller than $12 \mathrm{mg} / \mathrm{dL}$. A larger mean reduction was observed (WMD: $-2.501, \mathrm{CI}$ : -2.994 to $-2.009, P<0.001$, Fig. 2) when the baseline of $\mathrm{Ca}$ was $\geq 12 \mathrm{mg} / \mathrm{dL}$ compared to those $<12 \mathrm{mg} / \mathrm{dL}$ (WMD: -1.437 , CI: -1.629 to $-1.245, P<0.001$, Fig. 3$)$. The interaction was significant $(P<0.001)$ for the treatment effect between the baseline greater or smaller than $12 \mathrm{mg} / \mathrm{dL}$. Publication bias was not statistically significant $(P=0.7804)$. Meta-regression was used to explore the relationship of effect with age and the proportion of females in patients with $<12 \mathrm{mg} / \mathrm{dL}$. Age $(\beta=-0.0168$, CI: -0.035 to $0.0017, P=0.073$ ) and proportion of females $(\beta=-0.574, \mathrm{CI}:-1.65$ to $0.507, P=0.274)$ were not statistically significant when meta regressed with $\mathrm{Ca}$ level difference. In the pooled analysis of 166 patients, cinacalcet treatment significantly reduced $\mathrm{Ca}$ levels (WMD: $-1.65, \mathrm{CI}:-2.01$ to $-1.26, P<0.001$ ) compared to placebo.

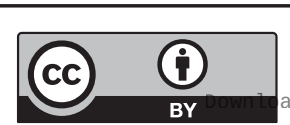

This work is licensed under a Creative Commons Attribution 4.0 International License. 


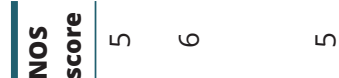

$\checkmark$ เ

ナ

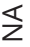
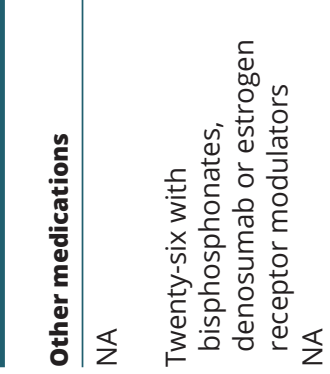

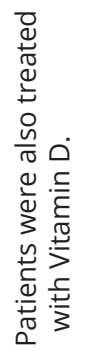
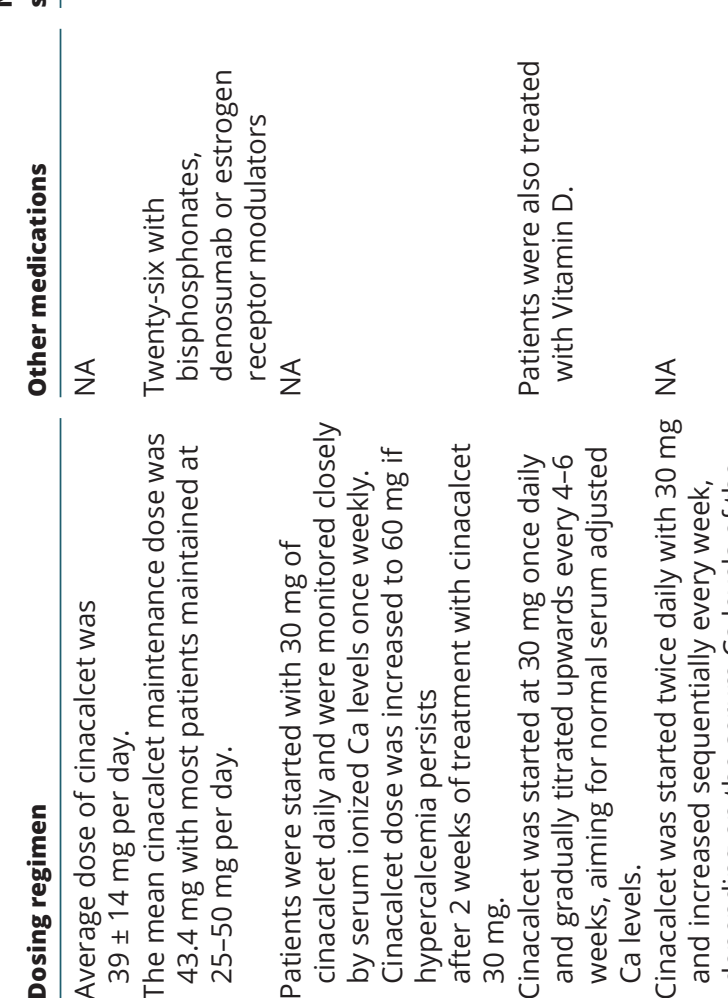

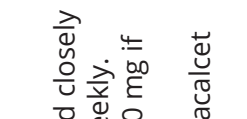

4 क ए

b. 논

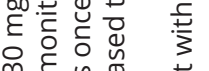

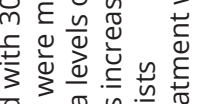

$>0$ ह

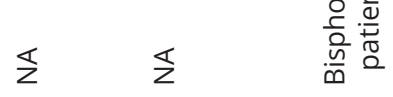

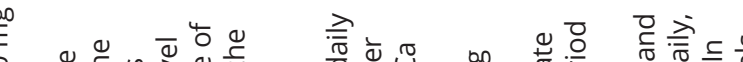

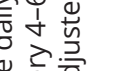

ठํ

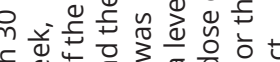

है

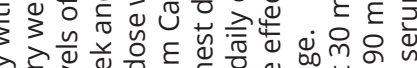

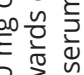

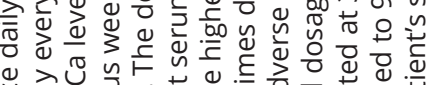

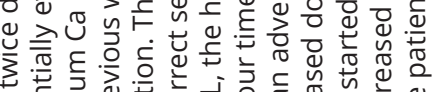

는 을

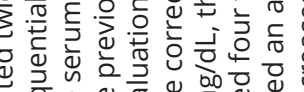

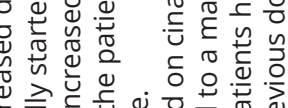

वृ

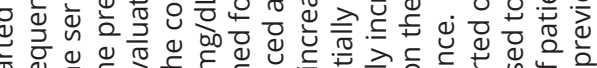

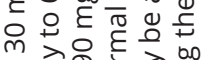

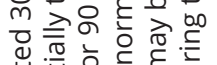

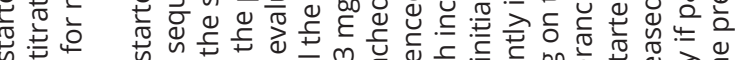

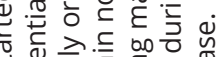

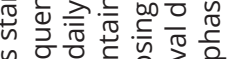

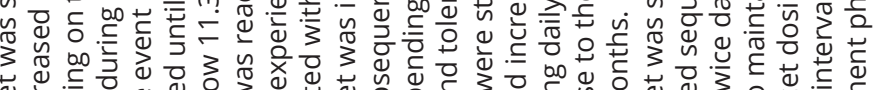

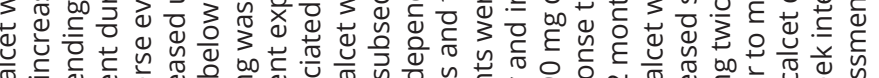

要

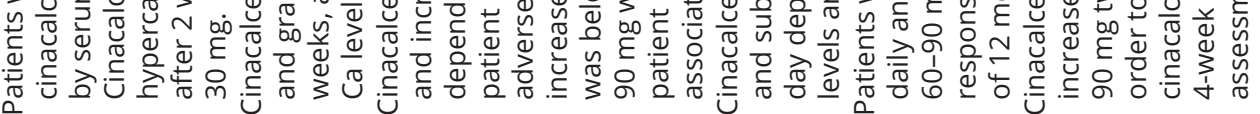

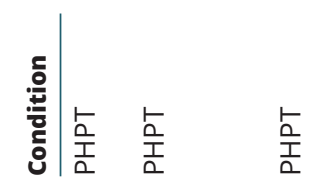

|

ชิ

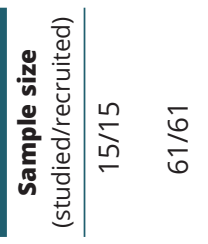

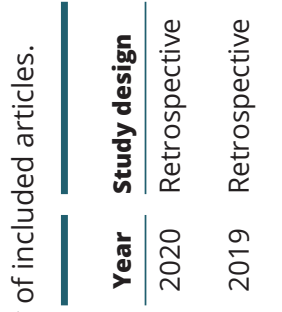

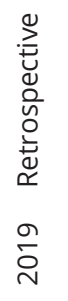

$\stackrel{ }{\stackrel{0}{5}}$

$\sum_{\risingdotseq}^{\infty} \stackrel{\infty}{\stackrel{\infty}{\infty}} \stackrel{\stackrel{N}{N}}{\infty}$

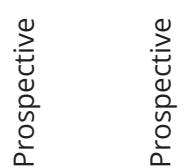

$\stackrel{\infty}{\grave{2}}$

๖ั

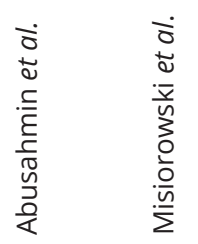

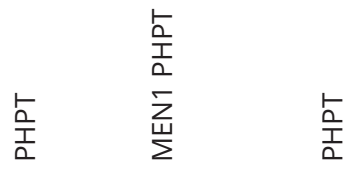

$\S$ \&

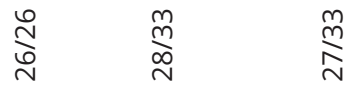

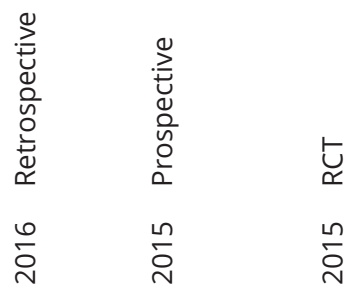

https://ec.bioscientifica.com

https://doi.org/10.1530/EC-20-0221 (c) 2020 The authors Published by Bioscientifica Ltd

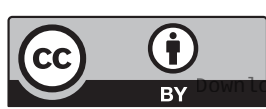

This work is licensed under a Creative Commons Attribution 4.0 International License. 


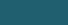

1
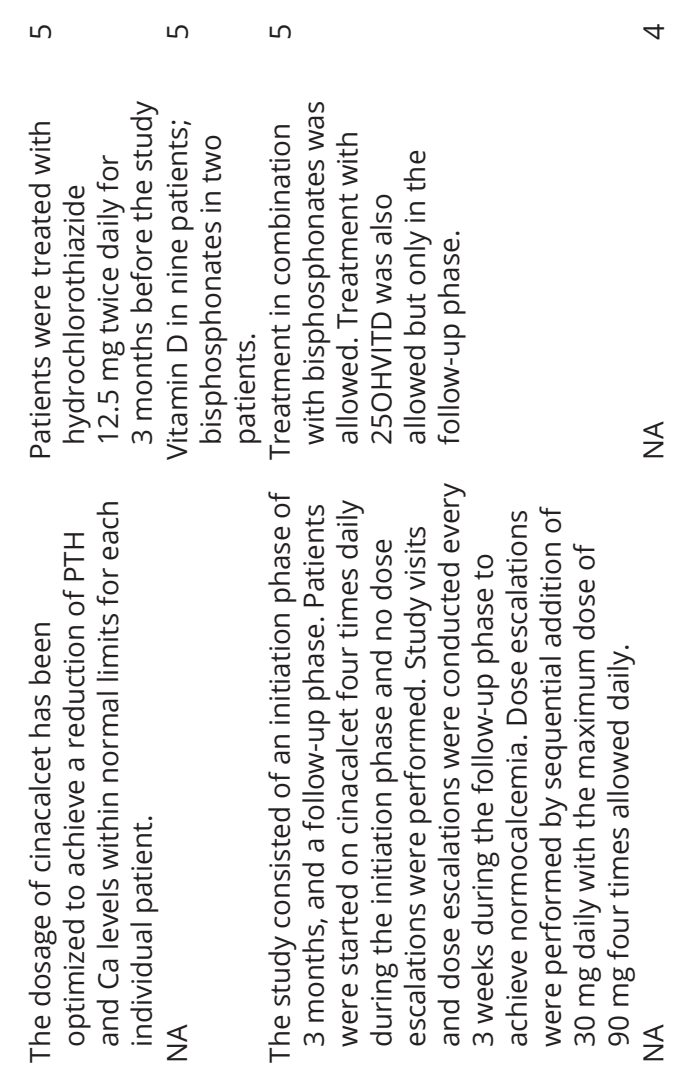

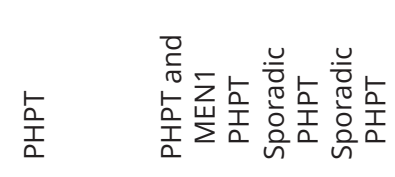

in $\underset{\substack{\infty \\ \infty}}{\infty} \leftleftarrows$

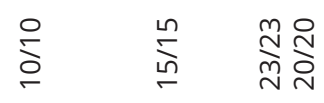

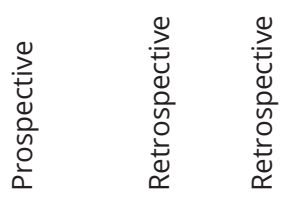

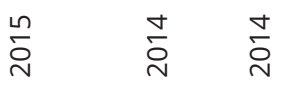

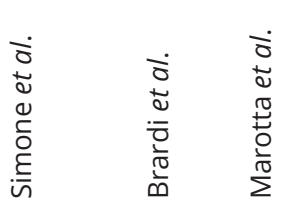

https://ec.bioscientifica.com

https://doi.org/10.1530/EC-20-0221

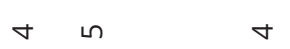

$\varangle$
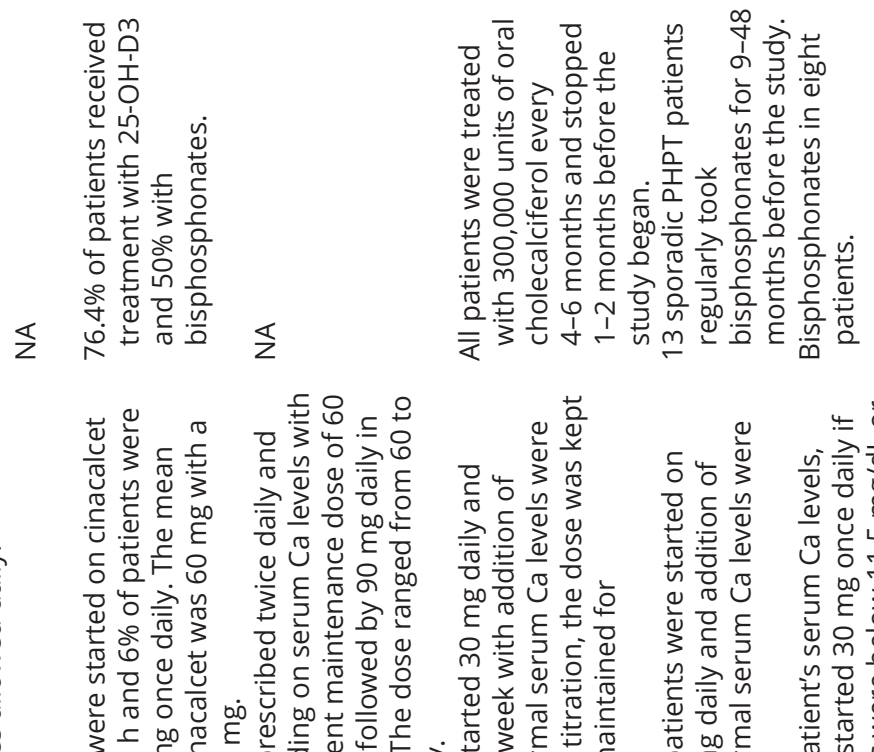

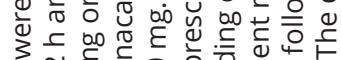

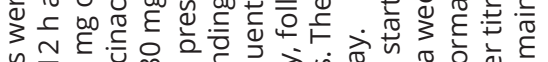

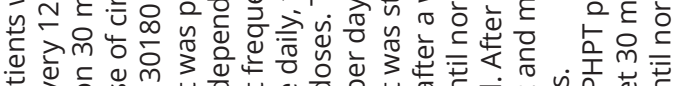

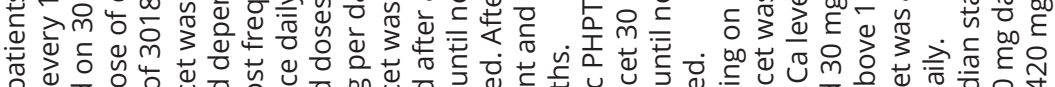

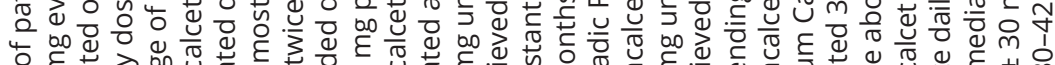

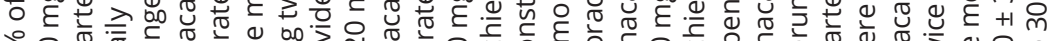

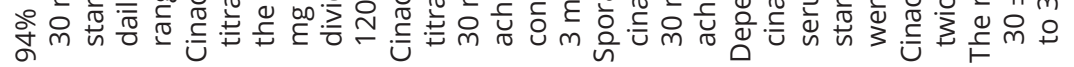

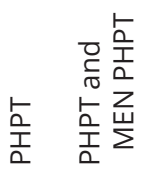

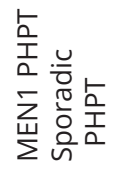

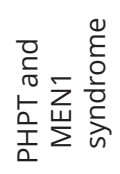

$\stackrel{m}{\text { Y }} \overline{6}$

ஸุ่

ח̊.

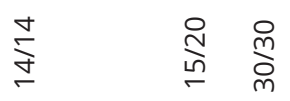

芩

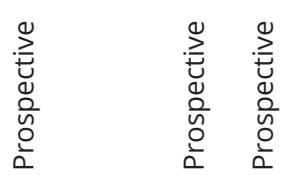

$\stackrel{\text { ก }}{\mathfrak{n}}$

$\stackrel{\text { ก }}{\sim}$

$\overline{\bar{\sigma}} \overline{\bar{\sigma}}$

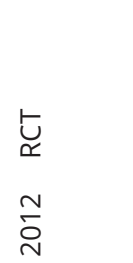

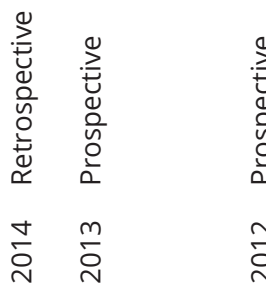

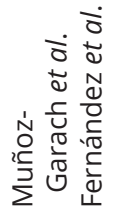

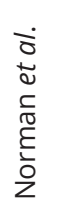
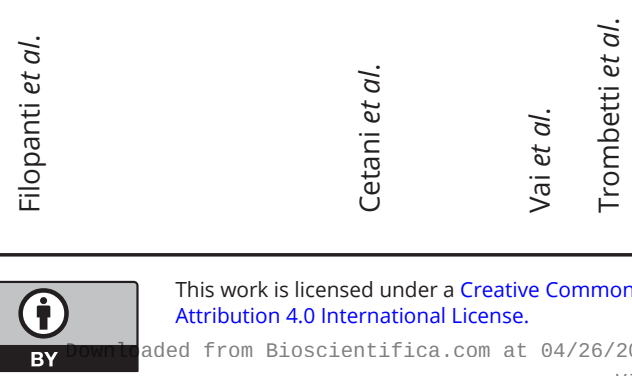

This work is licensed under a Creative Commons Attribution 4.0 International License. 


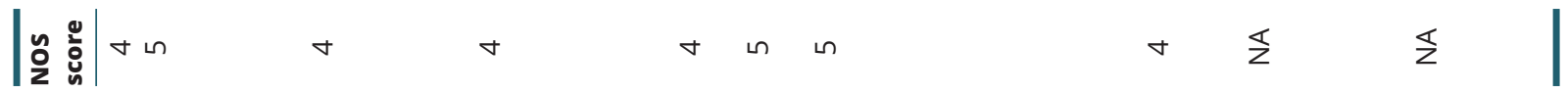
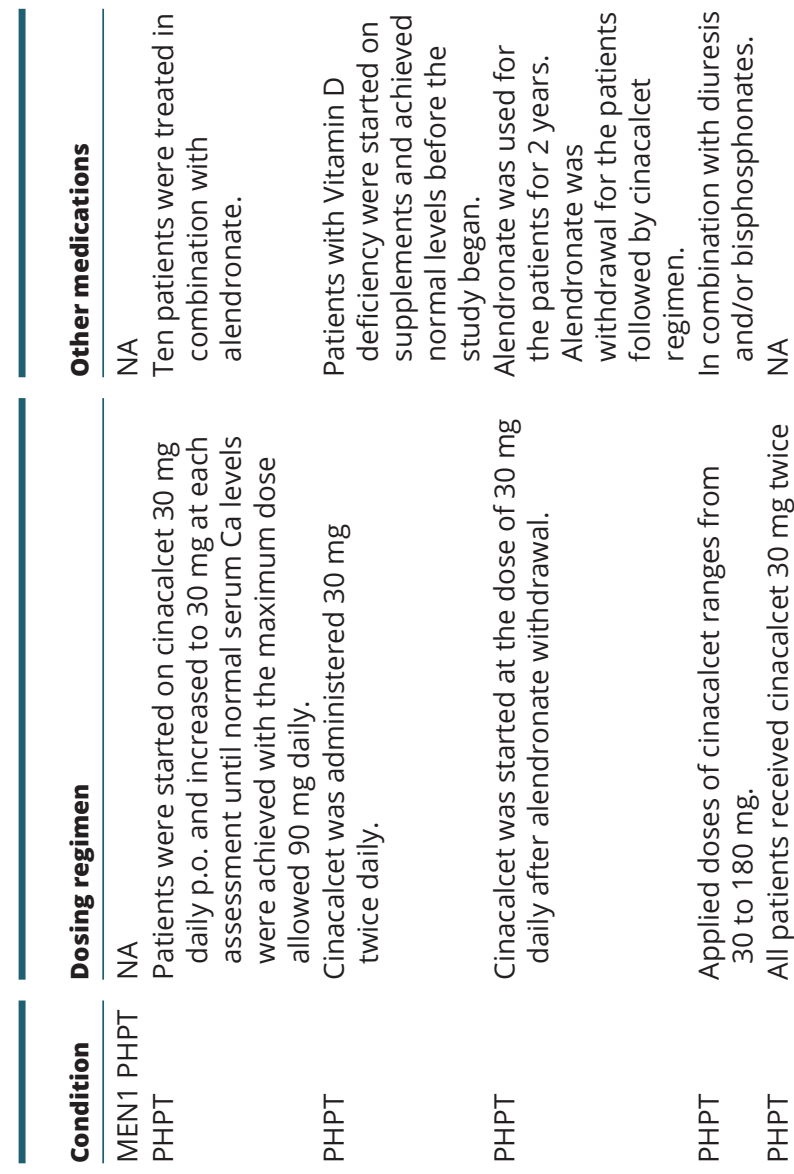

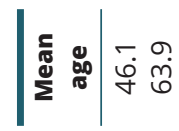

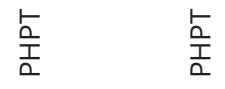

놈

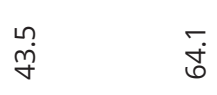

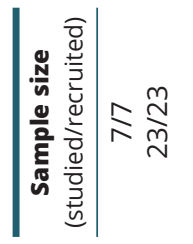

$\stackrel{\infty}{\infty} \quad \stackrel{Ð}{\lessgtr}$

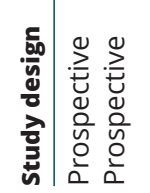

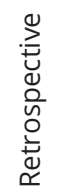

离

$\dot{0}$
$\frac{0}{2}$
$\stackrel{0}{0}$
0
0
$\frac{0}{0}$
$\frac{0}{\circ}$

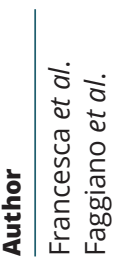

웅

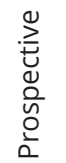

$\stackrel{\circ}{\stackrel{2}{2}}$

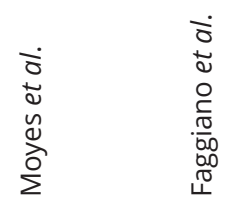

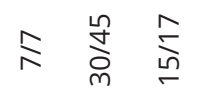

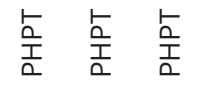

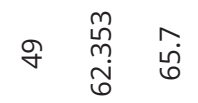

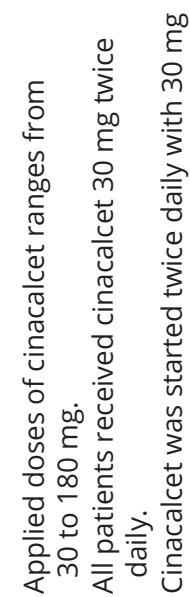

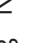

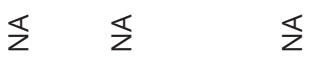

vi

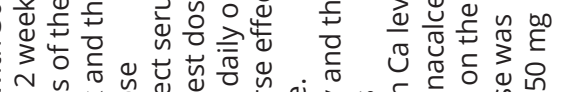

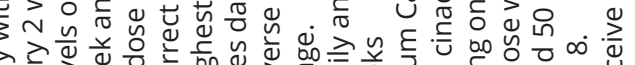

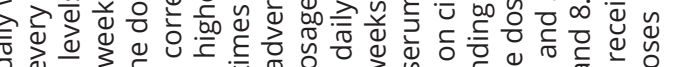

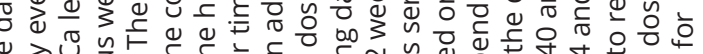

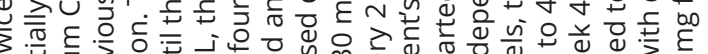

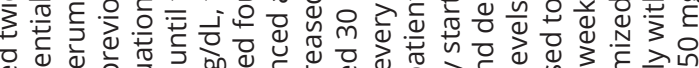

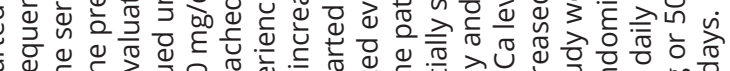

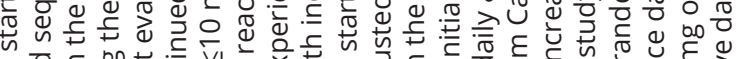

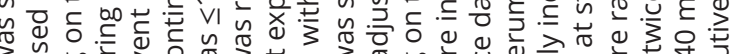

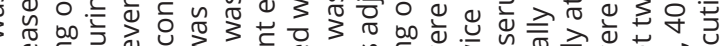

d.

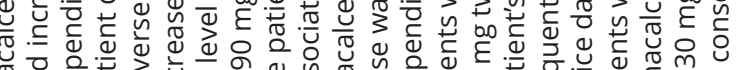

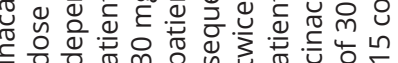

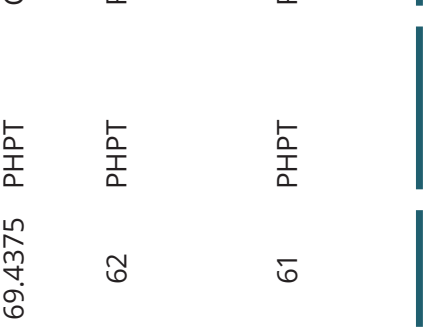

$\sum_{\infty}^{\infty} \quad \stackrel{0}{i} \quad \stackrel{6}{\leftarrow}$
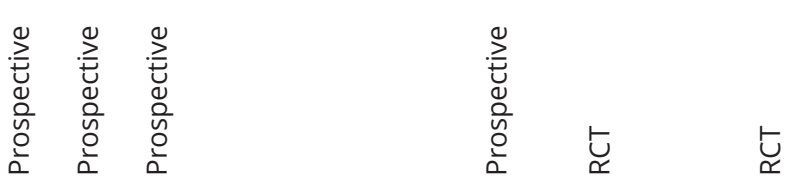

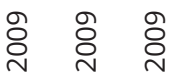

ஓ্ণ

ֻें

$\frac{0}{6}$

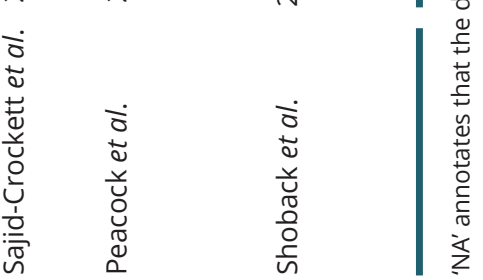




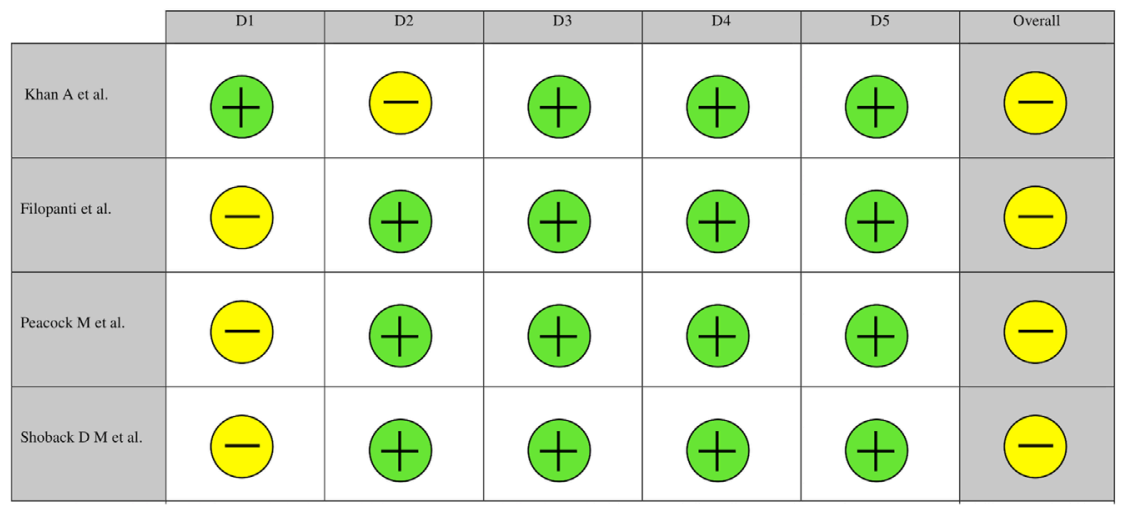

\section{Figure 2}

Cochrane risk of bias assessment of included articles.

\section{Parathyroid hormone (pg/mL)}

Treatment with cinacalcet normalized PTH level in 10\% (CI: 0.02 to 0.23 ) of the patients and the pooled mean post-treatment PTH levels was $95.276 \mathrm{pg} / \mathrm{mL}$ (CI: 83.131 to 107.420 ). The reduction of PTH was significantly different (WMD: -31.218, CI: -41.671 to -20.765 , $P<0.001$, Fig. 4). Publication bias by Egger's regression was significant $(P=0.0211)$. Meta regression with age and gender was not significant ( $\beta=-0.9176, \mathrm{CI}:-2.28$ to 0.446 , $P=0.187$ and $\beta=-2.264$, CI: -71.67 to $67.14, P=0.949$ ). In the pooled analysis of 166 patients, cinacalcet significantly reduced PTH level (WMD: -26.796, CI: -39.647 to $-13.945, P<0.001)$ compared to placebo.

\section{Phosphate (mg/dL)}

The mean phosphate level was 3.069 (CI: 2.882 to 3.256 ) after treatment with cinacalcet. The phosphate level significantly increased after cinacalcet treatment (WMD: 0.498, CI: 0.400 to $0.596, P<0.001$, Fig. 5). Publication bias was not statistically significant $(P=0.4589)$. Age and proportion of females did not modify the treatment effect of cinacalcet on phosphate levels ( $\beta=0.009$, CI: -0.0107 to $0.029, P=0.327$ and $\beta=-0.294$, CI: -0.690 to $1.278, P=0.524$, respectively). In the pooled analysis of 166 patients, cinacalcet significantly reduced phosphate levels (WMD: 0.634, CI: 0.445 to $0.824, P<0.001)$ compared to placebo.

\section{Discontinuation and adverse reaction}

In general, most adverse reactions were mild or moderate, mainly affecting the gastrointestinal system. The incidence rate of nausea or vomiting was $23 \%$ (CI: 0.14 to 0.33 ) and hypocalcemia was $3 \%$ (CI: 0.01 to 0.06 ). Most hypocalcemia cases reported were either asymptomatic or mild.

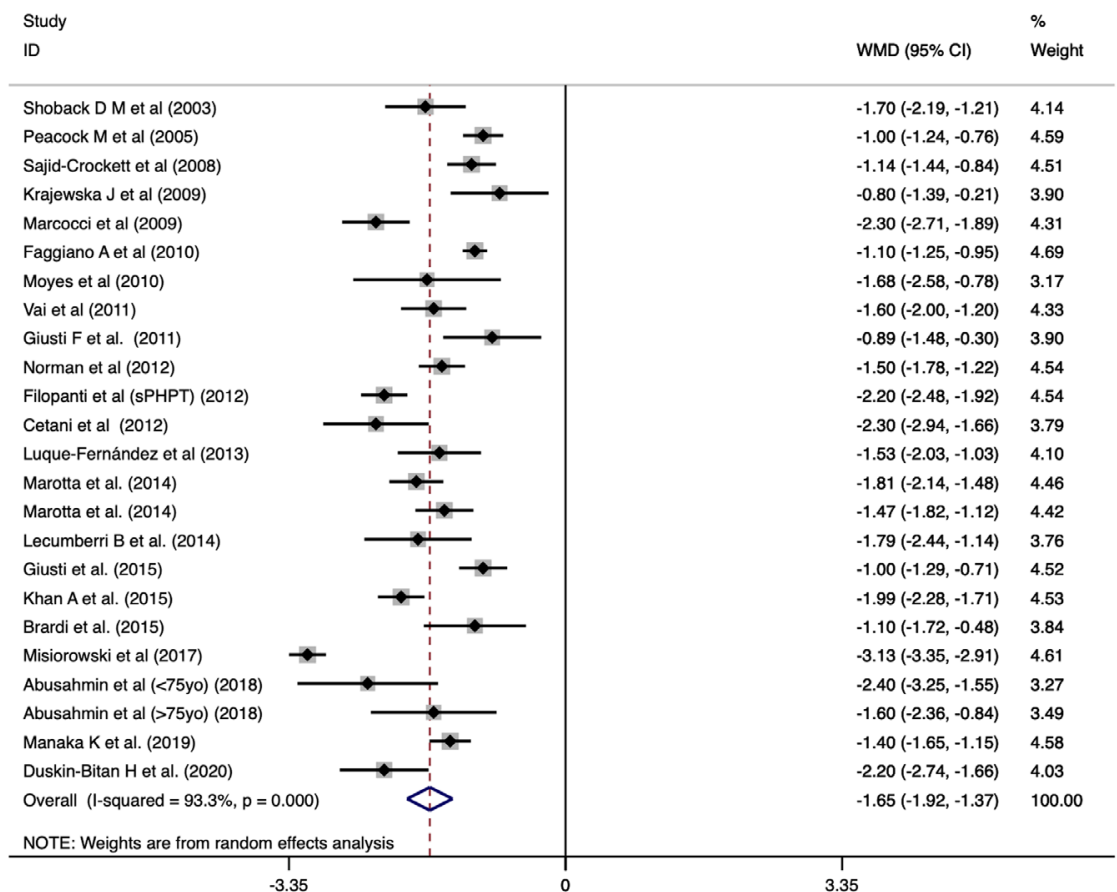

$-3.35$ (c) 2020 The authors Published by Bioscientifica Ltd https://ec.bioscientifica.com

https://doi.org/10.1530/EC-20-0221

\section{Figure 3}

Forest plot of Ca levels before and after cinacalcet with Dersimonian and Laird random effects model. 


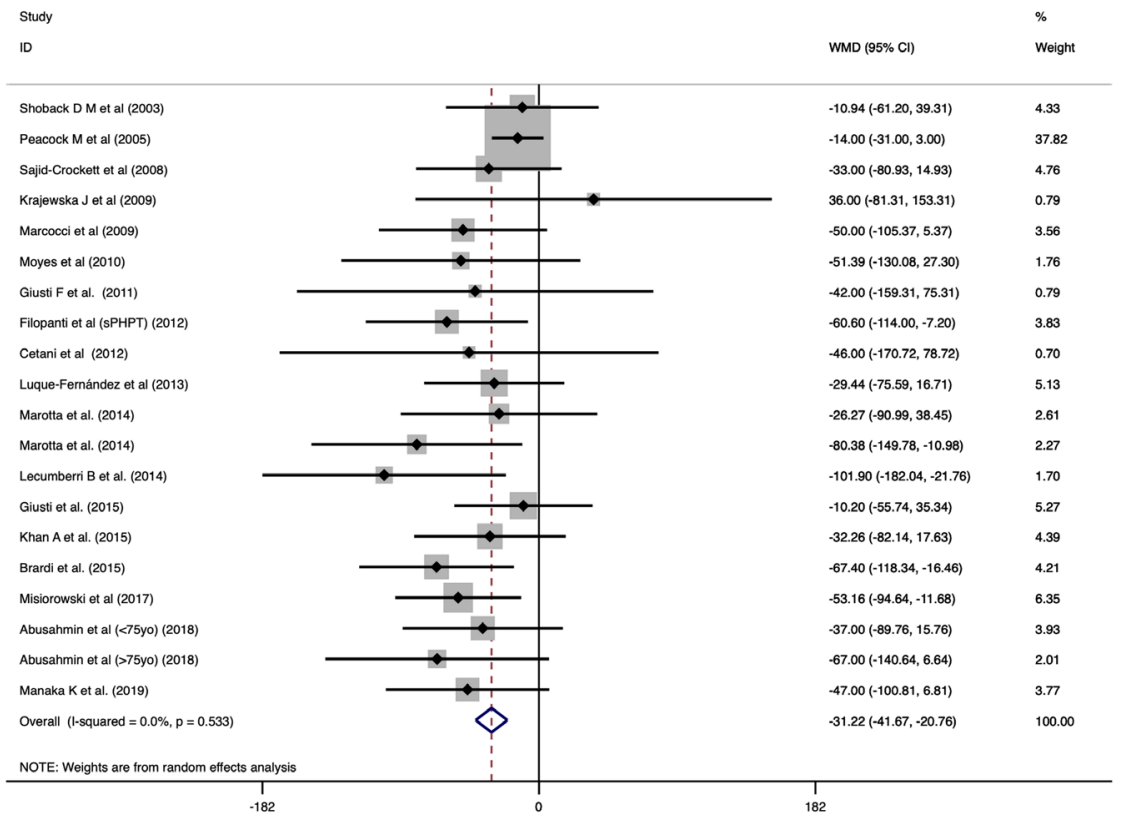

\section{Figure 4}

Forest plot of PTH levels before and after cinacalcet with Dersimonian and Laird random effects model.
However, one patient was referred to surgery after being hospitalized twice for symptomatic hypocalcemia (27). Paresthesia was also relatively uncommon with 19\% (CI: 0.08 to 0.31 ) incidence. Other adverse reactions include muscle spasm/cramps $(3.318 .2 \%)(22,31)$ and headache (23\%) (37). Most patients were able to continue treatment despite the adverse reactions, and only a minority withdrew treatment $(17,18,24,25,37)$.

\section{Discussion}

To our best knowledge, this is the first meta-analysis of the use of cinacalcet in PHPT. The favourable outcomes on serum calcium, PTH and phosphate levels provide support of the use of cinacalcet in PHPT as a bridging therapy while awaiting surgery and as a potential non-surgical treatment option for PHPT. We recognise that parathyroidectomy is the mainstay therapy for most patients with PHPT. However, parathyroidectomy could result in persistent postoperative hypocalcemia and, for some patients, hypercalcemia persists. In elderly patients with PHPT, the higher operative risk from comorbidities might deem them not suitable for surgery or delay the timing to surgery $(44,45)$. Also, the success of parathyroidectomy depends on the pre-operative localization of the culprit parathyroid gland which can be challenging.

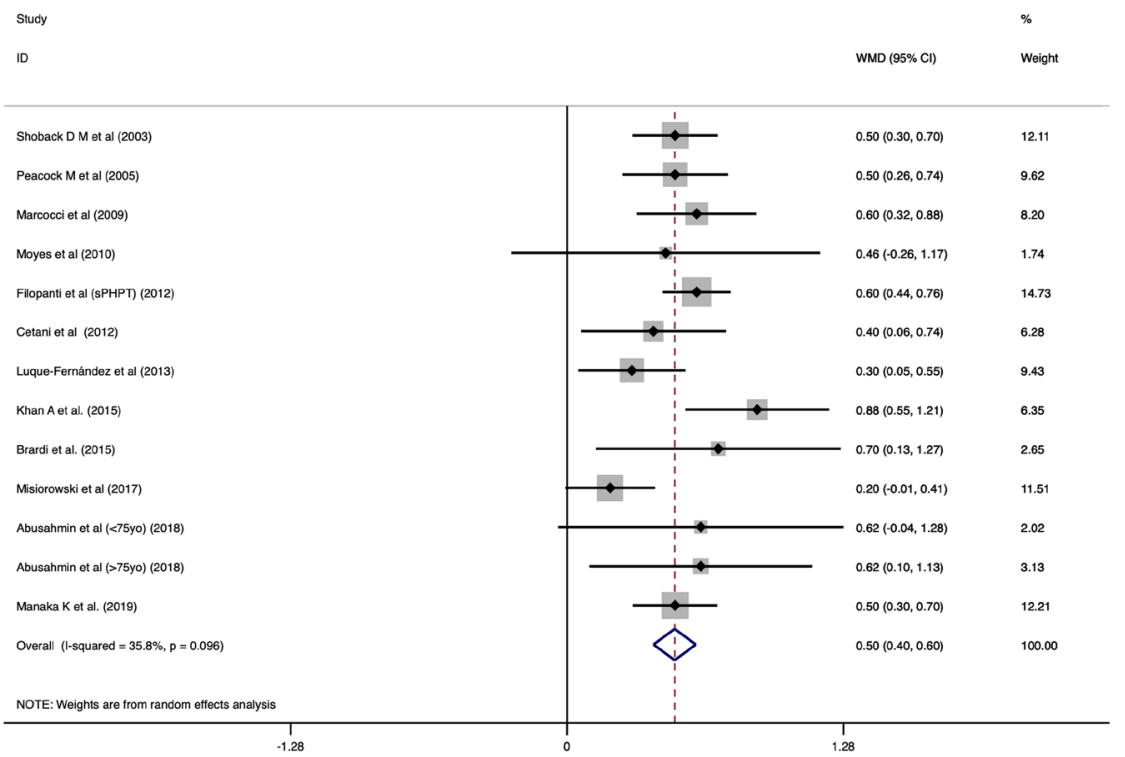

Figure 5

Forest plot of phosphate levels before and after cinacalcet with Dersimonian and Laird random effects model. https://ec.bioscientifica.com

https://doi.org/10.1530/EC-20-0221 (c) 2020 The authors Published by Bioscientifica Ltd

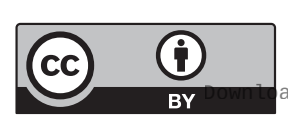

This work is licensed under a Creative Commons Attribution 4.0 International License. 
Medical therapy for PHPT, such as calcitonin or antiresorptive therapy (bisphosphonates or denosumab), has a modest effect on hypercalcemia level and is often shortlived (46).

In our meta-analysis, the use of cinacalcet significantly reduced the serum levels of $\mathrm{Ca}$ and normalization of $\mathrm{Ca}$ level was achieved in nearly $90 \%$ of patients. The reduction in Ca levels was accompanied by an increase in phosphate levels indicating that cinacalcet treatment can restore normal Ca homeostasis. Interestingly, Silverberg et al. observed that the largest reduction of serum $\mathrm{Ca}$ was in patients with higher baseline Ca levels (47). Our study agrees with Silverberg et al., where a larger treatment effect was observed for a higher baseline serum $\mathrm{Ca}(12.0 \mathrm{mg} / \mathrm{dL}$ or higher). This finding is relevant, as people with serum Ca $12 \mathrm{mg} / \mathrm{dL}$ or higher usually present with neurological symptoms of hypercalcemia such as confusion and altered mental status, which necessitates medical treatment. For these select patients, cinacalcet is a reasonable option in the treatment regimen to control hypercalcemia. Whether cinacalcet would have a place in the immediate medical treatment of severe PTH-dependent hypercalcemia would warrant further study. It is also comforting that age and gender do not modify the treatment efficacy of cinacalcet.

While cinacalcet reduces circulating PTH levels, we found that there was a lack of change in the size of the parathyroid gland as reported in two studies. Faggiano et al. utilized ultrasonographic examination every 6 months for the 24-month study and reported no change in the size of the parathyroid gland (33). Peacock et al. extrapolated that, with the relatively stable dose throughout the 5 years of study, the cell mass or secretory function was likely to be constant (34). The reduction in the parathyroid gland size was observed in the rat models of secondary hyperparathyroidism and in patients with secondary hyperparathyroidism where cinacalcet treatment prevents hyperplasia of the parathyroid gland $(48,49)$. The effect of cinacalcet on size control of parathyroid glands in PHPT has not been studied. However, usually parathyroid adenoma or hyperplasia does not cause local symptoms, hence the benefits of cinacalcet in parathyroid gland size control is less critical.

Our meta-analysis shows that normalisation in PTH levels after cinacalcet therapy only occurred in $10 \%$ of patients. In contrary, surgical treatment (parathyroidectomy) has reported 63\% normalization rates (50). There are several explanations to this difference. A likely mechanism explaining the lack of normalization in cinacalcet can be attributed to the physiological properties of PTH. The PTH is subjected to significant variation, affected by circadian, seasonal and pulsatile ultradian secretion (51). The secretion pattern can be altered in PHPT, with an increase in basal secretion and total PTH secreted every hour (52). Measurements of PTH levels which are typically done at fasting state can result in the underestimation of actual normalization rates. The 24-h PTH levels would provide a better estimate on the PTH levels, though impractical. The lack of normalization of PTH with cinacalcet could also be due to increased secretion of PTH peptide fragments (active or inactive) from increased intracellular degradation of PTH. Also, cinacalcet treatment is usually titrated to improve hypercalcemia to a level that is less harmful to patients, but not toward the normalization of PTH level. Nonetheless, the lack of PTH suppression argues against the long-term use for PHPT due to unopposed PTH effects on skeletal complications. The effects of cinacalcet on fracture risk, urinary $\mathrm{Ca}$ excretion, and kidney stones are less clear, but less critical if cinacalcet is used as bridging therapy. However, these information including longitudinal quality-of-life measures would be important if cinacalcet is used as a long-term alternative to surgery to control hypercalcemia in mild to moderate PHPT. The use of cinacalcet for patients with PHPT in combination with anti-resorptive to control hypercalcemia and to improve skeletal health from elevated PTH level would warrant further investigations.

Regarding cinacalcet adverse reactions, the reported cases are relatively small. The majority were classified as mild to moderate severity and were relatively uncommon to result in withdrawal from treatment. Nausea or vomiting accounted for the largest adverse event reported, occurring in 23\% (CI: 0.14 to 0.33 ) of the population studied which can be treated with anti-emetics. However, care should be taken to avoid drugs that can prolong the QT interval in the setting of possible hypocalcemia (53). Other adverse drug reactions included hypocalcemia (3\% CI: 0.01 to 0.06 ), paresthesia (19\%, CI: 0.08 to 0.31) and muscle spasm. Although rare, severe hypocalcemia after cinacalcet has been associated with higher baseline serum PTH levels (54). It may be a result of over suppression of PTH or abrupt lowering of PTH secondary to enhanced activation of CaSR (53). As a whole, hypocalcemia experienced after cinacalcet is generally mild and asymptomatic, and dose adjustment of cinacalcet is generally sufficient to prevent severe hypocalcemia. Importantly, the use of cinacalcet does not guarantee hypercalcemia treatment success, although there are cases of spontaneous remission of PHPT reported by Manaka et al. and Ferrari et al. $(17,55)$.

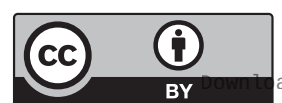

This work is licensed under a Creative Commons Attribution 4.0 International License. ded from Bioscientifica.com at 04/26/2023 11:25:32AM 


\section{Limitations}

There are several limitations to this review. First, we only synthesized English language literature. Next, we included conference abstracts in the meta-analysis. This decision was made based on small sample sizes on the use of cinacalcet in the treatment of PHPT. While some have argued against the inclusion of grey literature in metaanalysis, the Cochrane Group recommends the inclusion of grey literature to reduce potential publication bias $(56,57)$. Additionally, the long-term use of cinacalcet as medical treatment for PHPT would need to consider the cost of cinacalcet and the long-term safety data.

\section{Conclusions}

In conclusion, this meta-analysis provides support for the use of cinacalcet as medical option to control hypercalcemia in patients with PHPT. The use of cinacalcet as a long-term treatment for patients who are not eligible for parathyroidectomy, patients with persistent disease after parathyroidectomy, or patients who decline parathyroidectomy is an interesting proposition and would require further investigations and cost consideration.

\section{Supplementary materials}

This is linked to the online version of the paper at https://doi.org/10.1530/ EC-20-0221.

\section{Declaration of interest}

The authors declare that there is no conflict of interest that could be perceived as prejudicing the impartiality of the research reported.

\section{Funding}

This research did not receive any specific grant from any funding agency in the public, commercial or not-for-profit sector

\section{Author contribution statement}

C M K and S P Y performed study conception and design. C H N, Y H C, $\mathrm{M} \mathrm{H}$ Q T and J X N involved in the acquisition of data. C M K, S P Y, J J K and $\mathrm{CHN}$ contributed to the analysis and interpretation of data. $\mathrm{CHN}, \mathrm{YHC}$, $M H Q T$, J X N, S P Y, J J K and C M K involved in drafting the manuscript. $S P Y, J J K$ and $C M K$ critically revised the manuscript.

\section{References}

1 Yeh MW, Ituarte PHG, Zhou HC, Nishimoto S, Liu I-LA, Harari A, Haigh PI \& Adams AL. Incidence and prevalence of primary hyperparathyroidism in a racially mixed population.
Journal of Clinical Endocrinology and Metabolism 20133 1122-1129. (https://doi.org/10.1210/jc.2012-4022)

2 Pallan S, Rahman MO \& Khan AA. Diagnosis and management of primary hyperparathyroidism. BMJ 2012344 e1013. (https://doi. org/10.1136/bmj.e1013)

3 Poon G. Cinacalcet hydrochloride (Sensipar). Proceedings 200518 181-184. (https://doi.org/10.1080/08998280.2005.11928062)

4 Moher D, Liberati A, Tetzlaff J, Altman DG \& PRISMA Group. Preferred reporting items for systematic reviews and meta-analyses: the PRISMA statement. PLoS Medicine 20096 e1000097. (https://doi. org/10.1371/journal.pmed.1000097)

5 Hozo SP, Djulbegovic B \& Hozo I. Estimating the mean and variance from the median, range, and the size of a sample. BMC Medical Research Methodology 20055 13. (https://doi.org/10.1186/1471-2288-5-13)

6 Wan X, Wang W, Liu J \& Tong T. Estimating the sample mean and standard deviation from the sample size, median, range and/or interquartile range. BMC Medical Research Methodology 201414135. (https://doi.org/10.1186/1471-2288-14-135)

7 Furukawa TA, Barbui C, Cipriani A, Brambilla P \& Watanabe N. Imputing missing standard deviations in meta-analyses can provide accurate results. Journal of Clinical Epidemiology 2006 59 7-10. (https://doi.org/10.1016/j.jclinepi.2005.06.006)

8 Nyaga VN, Arbyn M \& Aerts M. Metaprop: a Stata command to perform meta-analysis of binomial data. Archives of Public Health 201472 39. (https://doi.org/10.1186/2049-3258-72-39)

9 DerSimonian R \& Laird N. Meta-analysis in clinical trials. Controlled Clinical Trials 19867 177-188. (https://doi.org/10.1016/01972456(86)90046-2)

10 Harbord RM \& Higgins JPT. Meta-regression in Stata. STATA Journal 20088 493-519. (https://doi.org/10.1177/1536867X0800800403)

11 Knapp G \& Hartung J. Improved tests for a random effects metaregression with a single covariate. Statistics in Medicine 200322 2693-2710. (https://doi.org/10.1002/sim.1482)

12 Egger M, Smith GD, Schneider M \& Minder C. Bias in meta-analysis detected by a simple, graphical test. BMJ $1997 \mathbf{7 1 0 9} 629-634$. (https://doi.org/10.1136/bmj.315.7109.629)

13 Lagoo J, Singal R, Berry W, Gawande A, Lim C, Paibulsirijit S \& Havens J. Development and feasibility testing of a device briefing tool and training to improve patient safety during introduction of new devices in operating rooms: best practices and lessons learned. Journal of Surgical Research 2019244 579-586. (https://doi. org/10.1016/j.jss.2019.05.056)

14 Sterne JAC, Savović J, Page MJ, Elbers RG, Blencowe NS, Boutron I, Cates CJ, Cheng HY, Corbett MS, Eldridge SM, et al. RoB 2: a revised tool for assessing risk of bias in randomised trials. BMJ 2019366 14898. (https://doi.org/10.1136/bmj.14898)

15 McGuinness LA \& Higgins JPT. Risk-of-bias VISualization (robvis): An $\mathrm{R}$ package and Shiny web app for visualizing risk-of-bias assessments. Research Synthesis Methods 2020 [epub]. (https://doi.org/10.1002/ jrsm.1411)

16 Duskin-Bitan H, Nemirovsky N, Slutzky-Shraga I, Gorshtein A, MasriIraqi H, Robenshtok E, Diker-Cohen T, Singer J, Shimon I, Hirsch D, et al. Hyperparathyroidism in patients over 75: clinical characteristics and outcome. Is conservative treatment a safe alternative? Maturitas 2020135 47-52. (https://doi.org/10.1016/j.maturitas.2020.02.010)

17 Manaka K, Sato J, Kinoshita Y, Ito N, Fujita M, Iiri T, Nangaku M \& Makita N. Effectiveness and safety of cinacalcet for primary hyperparathyroidism: a single center experience. Endocrine Journal 201966 683-689. (https://doi.org/10.1507/endocrj.EJ19-0034)

18 Koman A, Ohlsson S, Bränström R, Pernow Y, Bränström R \& Nilsson IL. Short-term medical treatment of hypercalcaemia in primary hyperparathyroidism predicts symptomatic response after parathyroidectomy. British Journal of Surgery 2019106 1810-1818. (https://doi.org/10.1002/bjs.11319)

19 Giusti F, Cianferotti L, Gronchi G, Cioppi F, Masi L, Faggiano A, Colao A, Ferolla P \& Brandi ML. Cinacalcet therapy in patients

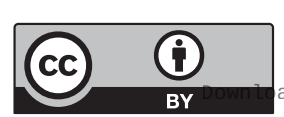

This work is licensed under a Creative Commons Attribution 4.0 International License. 
affected by primary hyperparathyroidism associated to multiple endocrine neoplasia syndrome type 1 (MEN1). Endocrine 201652 495-506. (https://doi.org/10.1007/s12020-015-0696-5)

20 García CR, Bover J, Da Silva I, Mercado C, Ballarin JA \& Rousaud F. Benefit of treatment with cinacalcet in patients with urolithiasis and primary hyperparathyroidism. Nephrology, Dialysis, Transplantation 201631 i377. (https://doi.org/10.1093/ndt/gfw184.2)

21 Marotta V, Di Somma C, Rubino M, Sciammarella C, Del Prete M, Marciello F, Ramundo V, Circelli L, Buonomano P, Modica R, et al. Potential role of cinacalcet hydrochloride in sporadic primary hyperparathyroidism without surgery indication. Endocrine 201549 274-278. (https://doi.org/10.1007/s12020-014-0381-0)

22 Khan A, Bilezikian J, Bone H, Gurevich A, Lakatos P, Misiorowski W, Rozhinskaya L, Trotman ML \& Toth M. Cinacalcet normalizes serum calcium in a double-blind randomized, placebo-controlled study in patients with primary hyperparathyroidism with contraindications to surgery. European Journal of Endocrinology 2015172 527-535. (https://doi.org/10.1530/EJE-14-0877)

23 Brardi S, Cevenini G, Verdacchi T, Romano G \& Ponchietti R. Use of Cinacalcet in nephrolithiasis associated with normocalcemic or hypercalcemic primary hyperparathyroidism: results of a prospective randomized pilot study. Archivio Italiano di Urologia, Andrologia 2015 87 66-71. (https://doi.org/10.4081/aiua.2015.1.66)

24 Lecumberri B, Meneses D, Pérez L, Álvarez-Escolá C, Torrijos A, Sanz Á, Cornejo JJ \& Pallardo LF. Characteristics and outcomes of patients with primary hyperparathyroidism treated with cinacalcet and followed in a tertiary hospital: a five-year retrospective study. Endocrine Reviews 201435 (Supplement) i1-i1153. (https://doi. org/10.1093/edrv/35.supp.1)

25 Munoz-Garach A, Fernandez-Garcia D, Del Valle-Torres MDM, GomezPerez AM, Sebastian-Ochoa A \& Tinahones-Madueño F. Imaging changes in 99MTC-MIBI in patients with primary hyperparathyroidism treated with cinacalcet. Journal of Bone and Mineral Research 201227 (Supplement 1) S1. (https://doi.org/10.1002/jbmr.1852)

26 Luque-Fernández I, García-Martín A \& Luque-Pazos A. Experience with cinacalcet in primary hyperparathyroidism: results after 1 year of treatment. Therapeutic Advances in Endocrinology and Metabolism 20134 77-81. (https://doi.org/10.1177/2042018813482344)

27 Norman J, Lopez J \& Politz D. Cinacalcet (Sensipar) provides no measurable clinical benefits for patients with primary hyperparathyroidism and may accelerate bone loss with prolonged use. Annals of Surgical Oncology 201219 1466-1471. (https://doi. org/10.1245/s10434-011-2065-9)

28 Filopanti M, Verga U, Ermetici F, Olgiati L, Eller-Vainicher C, Corbetta S, Persani L, Beck-Peccoz P \& Spada A. MEN1-related hyperparathyroidism: response to cinacalcet and its relationship with the calcium-sensing receptor gene variant Arg990Gly. European Journal of Endocrinology 2012167 157-164. (https://doi.org/10.1530/ EJE-12-0117)

29 Cetani F, Saponaro F, Banti C, Cianferotti L, Vignali E, Chiavistelli S, Viccica G, Pinchera A \& Marcocci C. Cinacalcet efficacy in patients with moderately severe primary hyperparathyroidism according to the European Medicine Agency prescription labeling. Journal of Endocrinological Investigation 201235 655-660. (https://doi. org/10.3275/7970)

30 Vai S, Dubini A, Persani L \& Bianchi ML. Cinalcalcet and bone mineral density in primary hyperparathyroidism with osteoporosis. Bone 201148 S243-S244. (https://doi.org/10.1016/j. bone.2011.03.590)

31 Trombetti A, Rizzoli R, Meier C, Henzen C, Torriani C, Rohrer A, Herrmann F, Braendle M, Christ E \& Kraenzlin M. European congress on osteoporosis \& osteoarthritis (ECCEO11-IOF): poster presentation abstracts. Osteoporosis International 201122 119-408. (https://doi. org/10.1007/s00198-011-1567-4)

32 Giusti F, Falchetti A, Masi L, Strigoli D, Leoncini G, Franceschelli F \& Brandi ML. Efficacy of cinacalcet therapy in patients affected by primary hyperparathyroidism associated to Multiple Endocrine Neoplasia Syndrome type 1 (MEN1). Preliminary results of the Florentine study. Journal of Bone and Mineral Research 201025 S225-S362. (https://doi.org/10.1002/jbmr.5650251304)

33 Faggiano A, Di Somma C, Ramundo V, Severino R, Vuolo L, Coppola A, Panico F, Savastano S, Lombardi G, Colao A, et al. Cinacalcet hydrochloride in combination with alendronate normalizes hypercalcemia and improves bone mineral density in patients with primary hyperparathyroidism. Endocrine 201139 283-287. (https://doi.org/10.1007/s12020-011-9459-0)

34 Peacock M, Bolognese MA, Borofsky M, Scumpia S, Sterling LR, Cheng $S$ \& Shoback D. Cinacalcet treatment of primary hyperparathyroidism: biochemical and bone densitometric outcomes in a five-year study. Journal of Clinical Endocrinology and Metabolism 200994 4860-4867. (https://doi.org/10.1210/jc.2009-1472)

35 Marcocci C, Chanson P, Shoback D, Bilezikian J, Fernandez-Cruz L, Orgiazzi J, Henzen C, Cheng S, Sterling LR, Lu J, et al. Cinacalcet reduces serum calcium concentrations in patients with intractable primary hyperparathyroidism. Journal of Clinical Endocrinology and Metabolism 200994 2766-2772. (https://doi.org/10.1210/jc.20082640)

36 Sajid-Crockett S, Singer FR \& Hershman JM. Cinacalcet for the treatment of primary hyperparathyroidism. Metabolism: Clinical and Experimental 200857 517-521. (https://doi.org/10.1016/j. metabol.2007.11.014)

37 Peacock M, Bilezikian JP, Klassen PS, Guo MD, Turner SA \& Shoback D. Cinacalcet hydrochloride maintains long-term normocalcemia in patients with primary hyperparathyroidism. Journal of Clinical Endocrinology and Metabolism 200590 135-141. (doi:10.1210/jc.2004-0842)

38 Shoback DM, Bilezikian JP, Turner SA, McCary LC, Guo MD \& Peacock M. The calcimimetic cinacalcet normalizes serum calcium in subjects with primary hyperparathyroidism. Journal of Clinical Endocrinology and Metabolism 200388 5644-5649. (doi:10.1210/ jc.2002-021597)

39 Abusahmin H, Surya A, Aldridge A, Okosieme O \& Das G. Cinacalcet: a viable therapeutic option for primary hyperparathyroidism in the elderly. Indian Journal of Endocrinology and Metabolism 201822 485-488. (https://doi.org/10.4103/ijem.IJEM_684_17)

40 Misiorowski W \& Zgliczyski W. Cinacalcet as symptomatic treatment of hypercalcaemia in primary hyperparathyroidism prior to surgery. Endokrynologia Polska 201768 306-310. (https://doi.org/10.5603/ EP.2017.0023)

41 Krajewska J, Paliczka-Cieslik E, Krawczyk A, Szpak-Ulczok S, Michalik B, Hasse-Lazar K \& Jurecka-Lubieniecka B. The results of cinacalcet therapy in patients with severe or refractory hypercalcemia due to primary hyperparathyroidism. Endocrine Abstracts 201020 P239. (available at: https://www.endocrine-abstracts.org/ea/0020/ ea0020p239)

42 Faggiano A, Di Somma C, Milone F, Ramundo V, Rota F, Vuolo L, Guerra E \& Colao A. Cinacalcet hydrochloride effectively controlled primary hyperparathyroidism in patients unresponsive to bisphosphonates. Endocrine Abstracts 201022 P405. (available at: https://www.endocrine-abstracts.org/ea/0022/ea0022p405)

43 Moyes VJ, Monson JP, Chew SL \& Akker SA. Clinical use of cinacalcet in MEN1 hyperparathyroidism. International Journal of Endocrinology 20102010 906163. (https://doi.org/10.1155/2010/906163)

44 Roche NA \& Young AE. Role of surgery in mild primary hyperparathyroidism in the elderly. British Journal of Surgery $2000 \mathbf{8 7}$ 1640-1649. (https://doi.org/10.1046/j.1365-2168.2000.01628.x)

45 Biertho L, Chu C \& Inabnet WB. Image-directed parathyroidectomy under local anaesthesia in the elderly. British Journal of Surgery 2003 90 738-742. (https://doi.org/10.1002/bjs.4175)

46 Hassan-Smith ZK, Criseno S \& Gittoes NJL. Mild primary hyperparathyroidism-to treat or not to treat? British Medical Bulletin 2019129 53-67. (https://doi.org/10.1093/bmb/ldy042) https://ec.bioscientifica.com https://doi.org/10.1530/EC-20-0221
(C) 2020 The authors Published by Bioscientifica Ltd

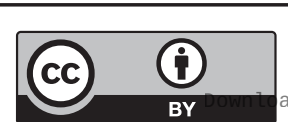

This work is licensed under a Creative Commons Attribution 4.0 International License. ded from Bioscientifica.com at 04/26/2023 11:25:32AM 
47 Silverberg SJ, Rubin MR, Faiman C, Peacock M, Shoback DM, Smallridge RC, Schwanauer LE, Olson KA, Klassen P \& Bilezikian JP. Cinacalcet hydrochloride reduces the serum calcium concentration in inoperable parathyroid carcinoma. Journal of Clinical Endocrinology and Metabolism 200792 3803-3808. (doi:10.1210/jc.2007-0585)

48 Komaba H, Nakanishi S, Fujimori A, Tanaka M, Shin J, Shibuya K, Nishioka M, Hasegawa H, Kurosawa T \& Fukagawa M. Cinacalcet effectively reduces parathyroid hormone secretion and gland volume regardless of pretreatment gland size in patients with secondary hyperparathyroidism. Clinical Journal of the American Society of Nephrology 20105 2305-2314. (https://doi.org/10.2215/CJN.02110310)

49 Miller G, Davis J, Shatzen E, Colloton M, Martin D \& Henley CM. Cinacalcet $\mathrm{HCl}$ prevents development of parathyroid gland hyperplasia and reverses established parathyroid gland hyperplasia in a rodent model of CKD. Nephrology, Dialysis, Transplantation 201227 2198-2205. (https://doi.org/10.1093/ndt/gfr589)

50 Pathak PR, Holden SE, Schaefer SC, Leverson G, Chen H \& Sippel RS. Elevated parathyroid hormone after parathyroidectomy delays symptom improvement. Journal of Surgical Research 2014190 119-125. (https://doi.org/10.1016/j.jss.2014.02.050)

51 Chiavistelli S, Giustina A \& Mazziotti G. Parathyroid hormone pulsatility: physiological and clinical aspects. Bone Research 20153 14049-14049. (https://doi.org/10.1038/boneres.2014.49)

52 Harms HM, Schlinke E, Neubauer O, Kayser C, Wüstermann PR, Horn R, Külpmann WR, von zur Mühlen A \& Hesch RD. Pulse amplitude and frequency modulation of parathyroid hormone in primary hyperparathyroidism. Journal of Clinical Endocrinology and Metabolism 199478 53-57. (https://doi.org/10.1210/ jcem.78.1.8288713)

53 Bover J, Ureña P, Ruiz-García C, daSilva I, Lescano P, del Carpio J, Ballarín J \& Cozzolino M. Clinical and practical use of calcimimetics in dialysis patients with secondary hyperparathyroidism. Clinical Journal of the American Society of Nephrology 201611 161-174. (https://doi.org/10.2215/CJN.01760215)

54 Floege J, Tsirtsonis K, Iles J, Drueke TB, Chertow GM \& Parfrey P. Incidence, predictors and therapeutic consequences of hypocalcemia in patients treated with cinacalcet in the EVOLVE trial. Kidney International 201893 1475-1482. (https://doi.org/10.1016/j. kint.2017.12.014)

55 Ferrari F, Marcocci C \& Cetani F. Acute severe primary hyperparathyroidism: spontaneous remission after 2 years follow-up. Journal of Endocrinological Investigation 201942 243-244. (https://doi. org/10.1007/s40618-018-0971-4)

56 Hopewell S, McDonald S, Clarke MJ \& Egger M. Grey literature in meta-analyses of randomized trials of health care interventions. Cochrane Database of Systematic Reviews 20072 MR000010. (https:// doi.org/10.1002/14651858.MR000010.pub3)

57 McKenzie JE, Brennan SE, Ryan RE, Thomson HJ, Johnston RV \& Thomas J. Defining the criteria for including studies and how they will be grouped for the synthesis. Cochrane Handbook for Systematic Reviews of Interventions 20193 33-65. (https://doi. org/10.1002/9781119536604.ch3)

Received in final form 5 June 2020

Accepted 3 July 2020

Accepted Manuscript published online 3 July 2020

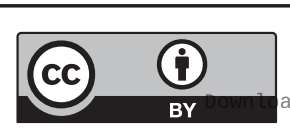

This work is licensed under a Creative Commons Attribution 4.0 International License.

ded from Bioscientifica.com at 04/26/2023 11:25:32AM 